\title{
Value of the MoCA Test as a Screening Instrument in Multiple Sclerosis
}

\author{
Emmanuelle Dagenais, Isabelle Rouleau, Mélanie Demers, Céline Jobin, \\ Élaine Roger, Laury Chamelian, Pierre Duquette
}

\begin{abstract}
Objective: Since a large proportion of multiple sclerosis (MS) patients exhibit cognitive deficits, it is important to have reliable and cost-effective screening measures that can be used to follow patients effectively. The objective of this study was to evaluate the clinical value of the Montreal Cognitive Assessment (MoCA) test in detecting cognitive deficits in MS patients. Methods: Forty-one (70.1\% women, mean age $44.51 \pm 7.43)$ mildly impaired (EDSS: $2.26 \pm 1.87$ ) MS patients were recruited for this study. In addition to the MoCA, they were administered the MSNQ-P (patient version) and the MSNQ-I (informant version), the BDI-FS and a comprehensive neuropsychological test battery. Results: There were significant correlations between the MoCA test and the three factors derived from the neuropsychological evaluation (Executive/speed of processing, Learning, Delayed recall). The MoCA test was correlated with the MSNQ-I but only marginally with the MSNQ-P. In addition, there was no significant correlation between the MSNQ$\mathrm{P}$ and the neuropsychological factors, whereas significant correlations were found between two of those factors (Learning and Delayed recall) and the MSNQ-I, suggesting that the informant version is more reliable than the patient version for the presence of cognitive deficits. Conclusion: The results obtained in the present study support the value of the MoCA test as a screening tool for the presence of cognitive dysfunction in MS patients, even in patients with mild functional disability (EDSS).
\end{abstract}

RÉSUMÉ: Valeur du test MoCA comme instrument de dépistage dans la sclérose en plaques. Objectif : Étant donné qu'une grande proportion des patients atteints de sclérose en plaques (SP) présentent des déficits cognitifs, il est important d'utiliser des mesures de dépistage fiables et économiques pour suivre ces patients efficacement. Le but de cette étude était d'évaluer la valeur clinique du MoCA pour détecter un déficit cognitif chez les patients atteints de SP. Méthode : Quarante et un patients atteints de SP avec déficit cognitif léger, dont 70,1\% étaient des femmes et dont l'âge moyen était de 44,51 \pm 7,43 ans, ont été inclus dans l'étude. En plus du MoCA, le MSNQ-P (version patient) et le MSNQ-I (version informateur), le BDI-FS et une batterie de tests neuropsychologiques ont été administrés aux patients. Résultats : Nous avons noté une corrélation significative entre le test MoCA et les trois facteurs dérivés de l'évaluation neuropsychologique (les fonctions exécutives/la vitesse du traitement de l'information, l'apprentissage, le rappel différé). Le MoCa était corrélé au MSNQ-I, mais seulement de façon marginale au MSNQ-P. De plus, il n'y avait pas de corrélation significative entre le MSNQ-P et les facteurs neuropsychologiques, alors que des corrélations significatives étaient présentes entre deux de ces facteurs (l'apprentissage et le rappel différé) et le MSNQ-I, ce qui suggère que la version informateur est plus fiable que la version patient en ce qui a trait à la présence de déficits cognitifs. Conclusion : Selon les résultats de cette étude, le test MoCA est un outil de dépistage utile pour mettre en évidence la présence d'une dysfonction cognitive chez les patients atteints de SP, même chez ceux qui présentent une invalidité fonctionnelle légère (EDSS).

Can J Neurol Sci. 2013; 40: 410-415

More than half of patients with multiple sclerosis (MS) exhibit cognitive deficits that mainly affect long-term memory, working memory, speed of information processing, attention and executive functions ${ }^{1-5}$. Those deficits have a direct impact on MS patients' employment status and quality of life ${ }^{6}$. Screening for such cognitive deficits is necessary to follow patients effectively. Therefore, there is an important need for reliable and costeffective screening tests in clinical practice.

Among the measures currently available for this purpose, the Multiple Sclerosis Neuropsychological Questionnaire (MSNQ) appears reliable to detect cognitive impairment ${ }^{7}$. This is particularly true for the MSNQ that is completed by an informant (MSNQ-I) ${ }^{7-10}$, since a high score on the MSNQ completed by the patient (MSNQ-P) correlates more with the score on the Beck Depression Inventory - Fast Screen (BDIFS) $)^{11}$, a measure of depression, than with objective measure of cognitive functions ${ }^{12}$. Reliability to detect cognitive deficits seems compromised when the patient presents with depressive affect $^{7}$. Moreover, as this is a self-reported measure, the MSNQ$\mathrm{P}$ allows only subjective assessment of cognitive functioning of the patient. However, it was shown that subjective perception of patients towards their cognitive skills is not always accurate, especially when they have moderate to severe cognitive impairment ${ }^{13}$.

It therefore seems important to perform testing using objective measures such as the Montreal Cognitive Assessment

From the Department of Psychology (ED, IR, MD), Université du Québec à Montréal Neurology Service (IR, CJ, ER, PD), Department of Psychiatry (LC), Hôpital NotreDame du CHUM; Neurology Service (CJ), Hôpital du Sacré-Cœur de Montréal, Montréal, Québec, Canada.

Received October 4, 2012. Final Revisions Submitted November 27, 2012. Correspondence to: Isabelle Rouleau, Department of Psychology, Université du Québec à Montréal, CP 8888, Succ. Centre-ville, Montréal, Québec, H3C 3P8, Canada. Email: rouleau.isabelle@uqam.ca. 
$(\mathrm{MoCA})^{14}$ or the Mini-Mental State Exam (MMSE) $)^{15}$ which are frequently used to screen for mild cognitive impairment (MCI) in the elderly. In this population, the MoCA is known for its high specificity and sensitivity for distinguishing MCI from Alzheimer's disease (AD) ${ }^{14,16}$. Conversely, the MMSE appears to be less sensitive to cognitive impairment in the elderly, possibly also in MS patients, because this measure does not include the attentional and executive functions which are areas most commonly affected by these conditions ${ }^{8,17}$.Thus, whereas the MoCA seems to be a promising avenue as a cognitive screening measure in MS, it remains to be examined. To our knowledge, no studies have been conducted to assess the value of this test within this population.

The objective of this study is to evaluate the clinical value of the MoCA in detecting cognitive deficits in MS patients. Results of the MoCA will be examined in relation to the scores obtained in a comprehensive neuropsychological assessment. In addition, scores on the MoCA will also be analyzed as a function of the scores obtained on the MSNQ to determine the consistency of findings obtained by objective (MoCA) and subjective (MSNQ) screening measures. It is expected that scores on the MoCA will be consistent with those obtained in the neuropsychological assessment, that is, patients with cognitive deficits will show lower scores on the MoCA. Moreover, it is expected that MoCA scores will show a higher correlation with MSNQ-I than with MSNQ-P, the former being more reliable to assess the presence of cognitive impairment in MS patients.

\section{Methods}

\section{Participants}

Forty-one patients with MS were recruited from the Multiple Sclerosis Clinic of Notre-Dame Hospital (CHUM). This study was approved by CHUM ethics committee and all patients signed an informed consent form. The demographic data and disease characteristics are presented in Table 1.

To be included in the project, patients had to meet the following criteria: (1) be suffering from multiple sclerosis (relapsing-remitting or secondary progressive) according to 2005 Revisions to the McDonald Diagnostic Criteria ${ }^{18}$; (2) aged between 18 and 55 years; (3) have French as their first language, or be fluent in that language; (4) have completed at least a high school degree; (5) be able to provide informed consent; (6) medications, such as stimulants (Modafinil, methylphenidate, Amantadine), acetylcholinesterase inhibitors, antidepressants with stimulant effects, benzodiazepines (regular use), were tolerated as long as the prescribed dose had been stable for at least one month prior to the study. Patients were excluded from the study if they had: (1) a history of neurological disorders other than MS, psychiatric or other serious medical conditions that may affect the neuropsychological performance (eg, traumatic brain injury, stroke); (2) a BDI-FS score greater than 4, indicating possible depression ${ }^{1}$; (3) a score on the EDSS (Expanded Disability Status Scale) greater than 7.5; (4) a history of developmental disorders (eg, ADD / ADHD, learning disabilities); (5) a history of alcohol or drug abuse; (6) sensory or motor deficits that may interfere with neuropsychological assessment; (7) experienced a MS relapse in the month prior to enrollment, or between screening and neuropsychological testing; (8) use of corticosteroids during the last 30 days, or use of analgesics which could interfere with cognitive performance.

\section{Procedures}

All evaluations took place at the Notre-Dame Hospital (CHUM). Patients were recruited from the MS Clinic during follow-up visits with their neurologist. All patients complaining of memory problems were referred to a research assistant. If they met inclusion criteria, the studywas explained to them and written consent was obtained for participation. The MoCA test was then administered and the BDI-FS was completed during this assessment to screen for depression. If all inclusion and exclusion criteria were met, patients were scheduled for a comprehensive neuropsychological evaluation with a neuropsychologist. Patients were handed questionnaires to be completed at home and brought back at the time of neuropsychological assessment.

On the day of the neuropsychological assessment, the patient met with the research assistant who reviewed all questionnaires to ensure completion. The Timed 25-Foot Walk Test was performed and patients were asked to complete the MSNQ-P

Table 1: Participants demographic data and disease characteristics

\begin{tabular}{l|c}
\hline & MS Patients \\
\hline Gender & \\
Women : N (\%) & $29(70.1 \%)$ \\
Men : N (\%) & $12(29.9 \%)$ \\
\hline Age & $44.51(7.43)$ \\
M (SD) & $12(29.3 \%)$ \\
\hline Education & $8(19.5 \%)$ \\
High School (12th grade); N (\%) & $21(51.2 \%)$ \\
College: N (\%) & $2.26(1.87)$ \\
University: N (\%) & $35(85.4 \%)$ \\
\hline EDSS & $6(14.6 \%)$ \\
M (SD)* & $13.49(6.79)$ \\
\hline MS Course & \\
Relapsing-remitting: N (\%) & $2.84(2.69)$ \\
Secondary Progressive: N (\%) & $33(80.5 \%)$ \\
\hline Disease Duration (years) & $8(19.5 \%)$ \\
M (SD) & \\
\hline Delay since last relapse (years) & \\
M (SD) & \\
\hline Treatment & \\
Immunosuppressant : N (\%) & \\
Untreated : N (\%) & \\
\hline
\end{tabular}

* Mean score with standard deviations in parenthesis; EDSS=Expanded Disability Status Scale; N=number of patients; SD=standard deviation 
(self) questionnaire and have a close family member or friend complete the MSNQ-I (informant) questionnaire.

The neuropsychological evaluation was administered in the morning. Cognitive tests were divided into two blocks and the order of administration was counterbalanced among the participants who were randomly assigned to each block. The order of motor testing (Purdue and 9-holes) was also reversed for half the subjects in order to reduce the effect of practice and fatigue.

\section{Measures}

\section{Screening tests and questionnaires}

Two measures commonly used as screening tests for cognitive deficits were examined: the MSNQ and the MoCA. The MSNQ was completed by the patient (MSNQ-P) and by one of his relatives (MSNQ-I). The MoCA test is a paper-and-pencil test freely available on the web for clinical and research purposes (www.mocatest.org) that can be administered in less than ten minutes ( $\mathrm{min}$ ) by health professionals and by trained nonmedical personal. Questionnaires assessing the patient's psychological state (anxiety, depression, and fatigue), health status or functioning at work were also handed. These included the Work Role Functioning Questionnaire (WRFQ) ${ }^{19}$, the Modified Fatigue Impact Scale (MFIS) ${ }^{20}$, the Pittsburgh Sleep Quality Index (PSQI) ${ }^{21}$, the Epworth Sleepiness Scale ${ }^{22}$, the Hospital Anxiety and Depression Scale (HADS) ${ }^{23}$ and the SF-36 Health survey questionnaire.

\section{Neuropsychological tests}

Our neuropsychological test battery included tests most often used in the assessment of MS patients ${ }^{24-26}$. Detailed descriptions of those tests can be found in Lezak et $\mathrm{al}^{27}$. Perceptual and visuo-constructional functions were evaluated using Benton Judgment of Line Orientation and copy of the Rey- Osterrieth Complex Figure (ROCF). Verbal memory was assessed with the Rey Auditory Verbal Learning Test (RAVLT) and two subtests of the Wechsler Memory Scale-III (logical stories and paired associates) while the ROCF immediate recall and delayed recall, the Brief Visual Memory Test (BVMT-R) and the 10/36 Spatial Recall Test were used as measures of visuospatial memory. Speed of information processing was assessed using the Conners Continuous Performance Test (CPT-II), the Symbol Digit Modalities Test (SDMT), and the Paced Auditory Serial Addition Test (PASAT). Executive functions were measured by the Trail Making Test (lines A and B), the verbal fluency task (phonemic: P, semantic: animals, alternating: vegetables-musical instruments) and by two subtests of the D-KEFS, the Color-Word Interference Test and the Sorting Test. Finally, motor function and visuo-motor coordination were assessed by the Nine-Hole Peg Test and the Purdue pegboard.

\section{Statistical Strategy}

To reduce the number of cognitive measures, neuropsychological tests results were grouped into factors. Factor analyses were first performed to determine the cognitive variables included in each factor. Reliability analyses (Cronbach's alpha: $\alpha$ ) were conducted to determine the internal
Table 2: List of the variables contributing to each cognitive factor

\begin{tabular}{l|l}
\hline \multicolumn{1}{c|}{ Factor } & \multicolumn{1}{c}{ Variables } \\
\hline $\begin{array}{l}\text { Executive/Speed } \\
\text { of information } \\
\text { processing }\end{array}$ & $\begin{array}{l}\text { Trail B (time), Stroop inhibition (time) } \\
\text { and flexibility (time), PASAT } \\
(2 \text { seconds and 3 seconds), SDMT } \\
\text { (60 and 90 seconds), }\end{array}$ \\
\hline Learning & $\begin{array}{l}\text { RAVLT (total), paired associates (total), } \\
\text { Logical memory (story A + story B, 2 } \\
\text { trial), Rey-O complex figure (immediate } \\
\text { recall), BVMT-R (total), Spatial } \\
\text { recall 10/36 (total). }\end{array}$ \\
\hline Delayed recall & $\begin{array}{l}\text { Delayed recall of the following tests: } \\
\text { RAVLT, paired associates, Logocam } \\
\text { memory : Stories A and B, Rey-O } \\
\text { complex figure, BVMT-R and } \\
\text { Spatial recall 10/36. }\end{array}$ \\
\hline
\end{tabular}

PASAT: Paced Auditory Serial Addition Task; SDMT: Symbol Digit Modalities Test; RAVLT: Rey Auditory Verbal Learning Test; BVMTR: Brief Visual Memory Test-Revised

validity of each factor. Three factors were obtained: (1) Executive/Speed of information processing $(\alpha=.87)$, (2) Learning $(\alpha=.79)$ and (3) Delayed recall $(\alpha=.81)$. The variables included in each factor are listed in Table 2. Subsequently, correlation coefficients (Pearson) were performed between (1) MoCA (total score) and MSNQ-I and MSNQ-P, (2) the total score BDI-FS vs. MoCA (total score) and MSNQ-I and MSNQ-P and (3) the result of each cognitive factors (Executive, learning, delayed recall) vs. the MoCA (total score and scores for sub-sections) and MSNQ-I and MSNQ-P.

\section{RESUlts}

According to the EDSS scores (Table 1) this population is rather mildly impaired by MS. Mean scores for the BDI-FS, the MoCA test and the MSNQs are presented in Table 3. Correlations obtained between MoCA, MSNQ, BDI-FS and the neuropsychological factors (Executive/Speed of processing, Learning, Delayed recall) are presented in Table 4.

\section{Relationship MSNQ-MoCA}

Even though there was a significant and moderate correlation between MSNQ-I and MSNQ-P ( $\mathrm{r}=.482, \mathrm{p}=.001$ ), only the MSNQ-I correlated significantly with the MoCA total score $(\mathrm{r}=-.390, \mathrm{p}=.012)$, although there was a tendency for MSNQ$\mathrm{P}$ to correlate with the MoCA test $(\mathrm{r}=-.300, \mathrm{p}=.056)$. The negative correlations observed suggest that the higher the score on the MoCA, the lower the score on the MSNQ. Informant perception of the patient's cognitive functioning appears to be more accurate than the patient's own perception. 
Table 3: Mean scores obtained in the BDI-FS, the MoCA and the MSNQ

\begin{tabular}{l|c}
\hline & MS Patients \\
\hline BDI-FS & \\
M (SD)* & $1.66(1.71)$ \\
Range of scores (Min - Max) & $0-7$ \\
\hline MoCA (total score) & \\
M (SD) & $26.02(2.30)$ \\
Range of scores (Min - Max) & $21-30$ \\
\hline MSNQ & \\
MSNQ-P, M (SD) & $21.20(10.13)$ \\
Range of scores (Min - Max) & $1-48$ \\
MSNQ-I, M (SD) & $17.28(11.79)$ \\
Range of scores (Min - Max) & $0-42$ \\
\hline
\end{tabular}

* Mean score with standard deviations in parenthesis

\section{Relationship with the BDI-FS}

Since the scores obtained on screening tests may be influenced by the patient's depressive affect, especially on selfreported measures such as the MSNQ-P $\mathrm{P}^{11,28}$, we first analyzed the relationship between BDI-FS and MSNQ-P. No significant correlation was found $(\mathrm{r}=-.031, \mathrm{p}=.847)$. Moreover, no significant correlation was obtained between the BDI-FS and the MSNQ-I $(\mathrm{r}=.084, \mathrm{p}=.601)$ or with the total score on the MoCA test $(\mathrm{r}=.231, \mathrm{p}=.146)$, in the present study. However, it should be taken into account that the average BDI-FS scores was very low $(\mathrm{M}=1.66, \mathrm{SD}=1.71)$, indicating that the majority of patients reported no or very little depressive affect.

Relationship between the MSNQ, the MoCA and the neuropsychological evaluation

None of the three cognitive factors (Executive/Speed of information processing, Learning and Delayed recall) correlated significantly with the MSNQ-P, indicating that the patient's perception of his cognitive functioning did not necessarily reflect the cognitive profile obtained through an objective evaluation. In contrast, significant and moderate correlations were obtained between the MSNQ-I and the Delayed recall factor $(\mathrm{r}=-.463, \mathrm{p}=.002)$ and the Learning factor $(\mathrm{r}=-.484, \mathrm{p}$ $=.001)$. Thus, patients who obtained lower performances on memory testing were rated by their informant as presenting more cognitive deficits. Contrary to expectation, there was no correlation between the MSNQ-I and the Executive/Speed of information processing factor $(\mathrm{r}=-.240, \mathrm{p}=.165)$. Thus, the MSNQ-I appears more sensitive to memory deficits than to executive and speed of information processing dysfunctions. Significant and moderate to high correlations were obtained between the MoCA total scores and the three cognitive factors: Learning $(\mathrm{r}=.686, \mathrm{p}<.001)$, Delayed recall $(\mathrm{r}=.636, \mathrm{p}<.001)$ and Executive/Speed of information processing factor $(\mathrm{r}=.367$, $\mathrm{p}=.030$ ). In addition, the score obtained on the memory section of the MoCA significantly and moderately correlated with the score obtained on the Learning factor $(\mathrm{r}=.419, \mathrm{p}=.006)$, and on the Delayed recall factor $(r=.419, \mathrm{p}=.006)$ while the score obtained on the Visuospatial/Executive section of the MoCA was significantly and moderately related to the performance on the Executive/Speed of information processing factor $(\mathrm{r}=.394, \mathrm{p}=$ $.019)$. These results support the construct validity of these sections of the MoCA.

Finally, MS patients were classified as cognitively intact or cognitively impaired based on the same general procedure described by Rao et $\mathrm{al}^{6}$. We calculated the percentage of MS patients who performed at or below $1.5 \mathrm{s.d}$. (or 7th percentile or scaled score $\leq 5$ ) of age-appropriate norms (Table 5). Patients were classified as "cognitively intact" if they had two or less failed measures and "cognitively impaired" if they failed on three or more measures. In our sample, 27 patients were considered "cognitively intact" and 14 were considered "cognitively impaired". There was a significant difference between the groups (intact vs. impaired) on EDSS scores (F $[1,40]=7,447, \mathrm{p}=.009$ eta $\left.^{2}=.16\right)$ and on MSNQ-I $(\mathrm{F}[1,40]$ $=4,143, \mathrm{p}=.049$, eta $\left.^{2}=.096\right)$, but not on MSNQ-P $(\mathrm{F}[1,40]=$ $0.350, p=.557)$. The difference between the groups on the MoCA test was highly significant $(\mathrm{F}[1,40]=17,084, \mathrm{p}<.001$, eta $^{2}=.305$ ).

Table 4: Correlations observed between MoCA, MSNQ, BDI-FS and neuropsychological factors

\begin{tabular}{|c|c|c|c|c|c|c|}
\hline & MSNQ-P & MSNQ-I & BDI-FS & Executive factor & Learning factor & Delayed recall factor \\
\hline $\begin{array}{c}\text { MoCA } \\
\text { (total score) }\end{array}$ & $\begin{array}{l}-.300 \\
(.056)\end{array}$ & $\begin{array}{l}-.390^{*} \\
(.012)\end{array}$ & $\begin{array}{c}.231 \\
(.146)\end{array}$ & $\begin{array}{l}.367^{*} \\
(.030)\end{array}$ & $\begin{array}{l}.686 * * * \\
(<.001)\end{array}$ & $\begin{array}{l}.636^{* * *} \\
(<.001)\end{array}$ \\
\hline MSNQ-P & - & $\begin{array}{l}.482 * * \\
(.001)\end{array}$ & $\begin{array}{l}-.031 \\
(.847)\end{array}$ & $\begin{array}{l}-.223 \\
(.197)\end{array}$ & $\begin{array}{l}-.025 \\
(.875)\end{array}$ & $\begin{array}{l}-.069 \\
(.668)\end{array}$ \\
\hline MSNQ-I & - & - & $\begin{array}{c}.084 \\
(.601)\end{array}$ & $\begin{array}{l}-.240 \\
(.165)\end{array}$ & $\begin{array}{c}-.484^{* *} \\
(.001)\end{array}$ & $\begin{array}{c}-.463 * * \\
(.002)\end{array}$ \\
\hline BDI-FS & - & - & - & $\begin{array}{l}.050 \\
(.777)\end{array}$ & $\begin{array}{c}.031 \\
(.845)\end{array}$ & $\begin{array}{c}.053 \\
(.740)\end{array}$ \\
\hline
\end{tabular}

$* \mathrm{p}<.05, * * \mathrm{p}<.01, * * * \mathrm{p}<.001$ 
Table 5: Results on the neuropsychological tests used to classify patients as cognitively intact or cognitively impaired

\begin{tabular}{|c|c|c|c|}
\hline & Mean (s.d.) & range & $\%$ with deficit* \\
\hline $\begin{array}{l}\text { RAVLT } \\
\text { - Total (trials 1-5) } \\
\text { - Delayed recall }\end{array}$ & $\begin{array}{c}48.15(8.19) \\
9.07(2.94)\end{array}$ & $\begin{array}{c}30-59 \\
1-14\end{array}$ & $\begin{array}{l}22.0 \% \\
14.6 \%\end{array}$ \\
\hline $\begin{array}{l}\text { Rey-O figure } \\
\text {-Immediate recall } \\
\text {-Delayed recall }\end{array}$ & $\begin{array}{l}17.87(5.88) \\
17.63(5.81) \\
\end{array}$ & $\begin{array}{l}5-30 \\
6-32 \\
\end{array}$ & $\begin{array}{l}24.4 \% \\
26.8 \% \\
\end{array}$ \\
\hline $\begin{array}{l}\text { 10/36 Spatial Recall Test } \\
\text { - Total (trials } 1-3 \text { ) } \\
\text { - Delayed recall }\end{array}$ & $\begin{array}{c}19.00(4.33) \\
6.37(2.30)\end{array}$ & $\begin{array}{l}9-27 \\
2-10\end{array}$ & $\begin{array}{l}24.4 \% \\
34.1 \%\end{array}$ \\
\hline PASAT total score $-3 \mathrm{sec} .(\mathrm{N}=38)^{*}$ & $42.74(12.62)$ & $22-66$ & $29.3 \%$ \\
\hline Trail B (time) & $78.19(35.5)$ & $32-213$ & $36.6 \%$ \\
\hline SDMT(90 sec.) & $50.17(10.03)$ & $27-79$ & $9.8 \%$ \\
\hline Verbal fluency (animals $90 \mathrm{sec}$.) & $22.80(4.98)$ & $14-36$ & $22.0 \%$ \\
\hline Sorting task (correct sorts) & $7.94(4.98)$ & $2-12$ & $19.5 \%$ \\
\hline
\end{tabular}

$*$ with $\leq 1.5$ s.d. or scaled score $\leq 5$ according to age-appropriate norms; **some patients were unable to perform the task, mean and s.d. based on those who completed the task, $\%$ with deficit includes those who did not complete the task. RAVLT: Rey Auditory Verbal Learning Test; PASAT: Paced Auditory Serial Addition Task; SDMT: Symbol Digit Modalities Test.

\section{Discussion}

The results obtained in the present study support the value of the MoCA test as a screening tool for the presence of cognitive dysfunction in MS patients, even in patients with mild functional disability (EDSS). These findings are consistent with the current literature on the MoCA test. Indeed, while its original purpose was to detect mild cognitive impairment (MCI) in elderly patients, the greater sensitivity of the MoCA test, compared to the MMSE, has been reported in other clinical populations such as patients with Huntington's disease ${ }^{29}$, Parkinson's disease ${ }^{30,31}$, stroke, ruptured aneurysm ${ }^{32,33}$, chronic heart failure $^{34}$ and Rapid Eye Movement (REM) Sleep Behavior Disorder ${ }^{35}$. In the present study, the value of the MoCA test as an objective screening tool in MS patients was confirmed by the highly significant difference observed in MoCA total score between cognitively intact and cognitively impaired patients. It was further supported by the significant correlations obtained between scores on specific sections of the MoCA test and the corresponding factors derived from the comprehensive neuropsychological evaluation, including executive functions.

The weak correlation between the MSNQ-P and the results of the neuropsychological testing has previously been reported ${ }^{7,10}$. In our study, the MSNQ-P was not correlated with the presence of depression (assessed by the BDI-FS) as it is often reported ${ }^{7,36}$. However, this might be due to the absence or the very low level of depression in our sample. Nevertheless, our patients' selfestimation of their cognitive deficits was only marginally correlated with an objective measure of their cognitive functioning. This is not specific to the MSNQ-P since we recently reported ${ }^{13}$ important discrepancies between objective and subjective assessment of cognitive functioning using the Prospective and Retrospective Memory Questionnaire ${ }^{22}$. In contrast, there was a strong correlation between the results obtained on the neuropsychological tests, at least for memory functioning, and the score on the MSNQ-I. These results are consistent with what has previously been reported ${ }^{7,36}$. The lack of correlation with executive functions was somewhat surprising since it is a domain frequently affected in MS. Since an informant is not always available, the use of an objective screening measure of cognitive functioning such as the MoCA appears a valuable clinical tool that can be used to select patients for a comprehensive neuropsychological evaluation.

The main limitation of our study is the small sample size and the small range of MoCA test scores. To further confirm the value of the MoCA as a clinically useful screening tool, the next step is to study its psychometric characteristics (cut-off score with measures of sensitivity and specificity) in a large sample of thoroughly investigated MS patients who would also be administered a neuropsychological battery sensitive to MS, such as the Minimal Assessment of Cognitive Function in Multiple Sclerosis (MACFIMS) ${ }^{26}$ or the Brief Repeatable Battery of Neuropsychological Tests (BRB-N) ${ }^{25}$.

\section{ACKNOWLEDGEMENTS}

This study was supported by an unrestricted grant from Biogen-Idec Canada and by a graduate scholarship (E.D.) from the Fonds de la recherche en santé du Québec (FRSQ).

\section{REFERENCES}

1. Chiaravalloti ND, DeLuca J. Cognitive impairment in multiple sclerosis. Lancet Neurol. 2008;7(12):1139-51.

2. Thornton AE, Raz N. Memory impairment in multiple sclerosis: a quantitative review. Neuropsychology. 1997;11(3):357-66.

3. Edgar C, Jongen PJ, Sanders E, et al. Cognitive performance in relapsing remitting multiple sclerosis: a longitudinal study in daily practice using a brief computerized cognitive battery. BMC Neurol. 2011;11:68

4. Winkelmann A, Engel C, Apel A, Zettl UK. Cognitive impairment in multiple sclerosis. J Neurol. 2007;254 Suppl 2:II35-42.

5. Ouellet J, Scherzer PB, Rouleau I, et al. Assessment of social cognition in patients with multiple sclerosis. J Int Neuropsychol Soc. $2010 ; 16(2): 287-96$ 
6. Rao SM, Leo GJ, Ellington L, Nauertz T, Bernardin L, Unverzagt F. Cognitive dysfunction in multiple sclerosis. II. Impact on employment and social functioning. Neurology. 1991;41(5): 692-6.

7. Benedict RH, Munschauer F, Linn R, et al. Screening for multiple sclerosis cognitive impairment using a self-administered 15-item questionnaire. Mult Scler. 2003;9(1):95-101.

8. Scherer P. Cognitive screening in multiple sclerosis. J Neurol. 2007; 254 Suppl 2:II26-9.

9. Benedict RH, Zivadinov R. Reliability and validity of neuropsychological screening and assessment strategies in MS. J Neurol. 2007;254 Suppl 2:II22-II5.

10. O'Brien A, Gaudino-Goering E, Shawaryn M, Komaroff E, Moore NB, DeLuca J. Relationship of the Multiple Sclerosis Neuropsychological Questionnaire (MSNQ) to functional, emotional, and neuropsychological outcomes. Arch Clin Neuropsychol. 2007;22(8):933-48.

11. Benedict RH, Fishman I, McClellan MM, Bakshi R, WeinstockGuttman B. Validity of the Beck Depression Inventory-Fast Screen in multiple sclerosis. Mult Scler. 2003;9(4):393-6.

12. Benedict RH, Zivadinov R. Predicting neuropsychological abnormalities in multiple sclerosis. J Neurol Sci. 2006;245(12):67-72.

13. Demers M, Rouleau I, Scherzer P, Ouellet J, Jobin C, Duquette P. Impact of the cognitive status on the memory complaints in MS patients. Can J Neurol Sci. 2011;38(5):728-33.

14. Nasreddine ZS, Phillips NA, Bedirian V, et al. The Montreal Cognitive Assessment, MoCA: a brief screening tool for mild cognitive impairment. J Am Geriatr Soc. 2005;53(4):695-9.

15. Folstein MF, Robins LN, Helzer JE. The Mini-Mental State Examination. Arch Gen Psychiatry. 1983;40(7):812.

16. Ismail Z, Rajji TK, Shulman KI. Brief cognitive screening instruments: an update. Int J Geriatr Psychiatry. 2010;25(2): $111-20$.

17. Beatty WW, Goodkin DE. Screening for cognitive impairment in multiple sclerosis. An evaluation of the Mini-Mental State Examination. Arch Neurol. 1990;47(3):297-301.

18. Polman CH, Reingold SC, Edan G, et al. Diagnostic criteria for multiple sclerosis: 2005 revisions to the "McDonald Criteria". Ann Neurol. 2005;58(6):840-6.

19. Durand MJ, Vachon B, Hong QN, Imbeau D, Amick BC 3rd, Loisel P. The cross-cultural adaptation of the Work Role Functioning Questionnaire in Canadian French. Int J Rehabil Res. 2004;27 (4):261-8.

20. Fisk JD, Pontefract A, Ritvo PG, Archibald CJ, Murray TJ. The impact of fatigue on patients with multiple sclerosis. Can J Neurol Sci. 1994;21(1):9-14.

21. Buysse DJ, Reynolds CF 3rd, Monk TH, Berman SR, Kupfer DJ. The Pittsburgh Sleep Quality Index: a new instrument for psychiatric practice and research. Psychiatry Res. 1989;28(2): 193-213.
22. Johns MW. A new method for measuring daytime sleepiness: the Epworth sleepiness scale. Sleep. 1991;14(6):540-5.

23. Snaith RP. The Hospital Anxiety and Depression Scale. Health Qual Life Outcomes. 2003;1:29.

24. Benedict RH, Bruce JM, Dwyer MG, et al. Neocortical atrophy, third ventricular width, and cognitive dysfunction in multiple sclerosis. Arch Neurol. 2006;63(9):1301-6.

25. Rao SM, Leo GJ, Bernardin L, Unverzagt F. Cognitive dysfunction in multiple sclerosis. I. Frequency, patterns, and prediction. Neurology. 1991;41(5):685-91.

26. Benedict RH, Fischer JS, Archibald CJ, et al. Minimal neuropsychological assessment of MS patients: a consensus approach. Clin Neuropsychol. 2002;16(3):381-97.

27. Lezak MD, Howieson DB, Bigler D, Tranel D. Neuropsychological Assessment. 5th ed. New-York: Oxford University Press; 2012.

28. Benedict RH, Carone DA, Bakshi R. Correlating brain atrophy with cognitive dysfunction, mood disturbances, and personality disorder in multiple sclerosis. J Neuroimaging. 2004;14(3 Suppl):36S-45S.

29. Videnovic A, Bernard B, Fan W, Jaglin J, Leurgans S, Shannon KM. The Montreal Cognitive Assessment as a screening tool for cognitive dysfunction in Huntington's disease. Mov Disord. 2010;25(3):401-4

30. Gill DJ, Freshman A, Blender JA, Ravina B. The Montreal cognitive assessment as a screening tool for cognitive impairment in Parkinson's disease. Mov Disord. 2008;23(7): 1043-6.

31. Hoops S, Nazem S, Siderowf AD, et al. Validity of the MoCA and MMSE in the detection of MCI and dementia in Parkinson disease. Neurology. 2009;73(21):1738-45.

32. Schweizer TA, Al-Khindi T, Macdonald RL. Mini-Mental State Examination versus Montreal Cognitive Assessment: rapid assessment tools for cognitive and functional outcome after aneurysmal subarachnoid hemorrhage. J Neurol Sci. 2012;316 (1-2): $137-40$

33. Godefroy O, Fickl A, Roussel M, et al. Is the Montreal Cognitive Assessment superior to the Mini-Mental State Examination to detect poststroke cognitive impairment? A study with neuropsychological evaluation. Stroke. 2011;42(6):1712-16.

34. Cameron J, Worrall-Carter L, Page K, Stewart S, Ski CF. Screening for mild cognitive impairment in patients with heart failure: Montreal Cognitive Assessment versus Mini Mental State Exam. Eur J Cardiovasc Nurs. 2012. [Epub ahead of print]

35. Gagnon JF, Postuma RB, Joncas S, Desjardins C, Latreille V. The Montreal Cognitive Assessment: a screening tool for mild cognitive impairment in REM sleep behavior disorder. Mov Disord. 2010;25(7):936-40.

36. Benedict RH, Cox D, Thompson LL, Foley F, Weinstock-Guttman B, Munschauer F. Reliable screening for neuropsychological impairment in multiple sclerosis. Mult Scler. 2004;10(6):675-8. 